\title{
Implementasi Kombinasi Algoritma RSA dan Algoritma DES Pada Aplikasi Pengaman Pesan Teks
}

\author{
Adriansyah Tampubolon \\ Program Studi Teknik Informatika Fakultas Teknik dan \\ Komputer Universitas Harapan Medan
}

\begin{tabular}{|c|c|}
\hline Article Info & $\begin{array}{l}\text { ABSTRACT } \\
\end{array}$ \\
\hline $\begin{array}{l}\text { Article history: } \\
\text { Received Jul 12 } \\
\text { Revised Aug } 2020 \\
\text { th }, 2020 \\
\text { Accepted Oct } 26^{\text {th }}, 2020\end{array}$ & $\begin{array}{l}\text { Kriptografi adalah ilmu yang mempelajari teknik matematis yang } \\
\text { berhubungan dengan aspek keamanan informasi seperti tingkat keyakinan, } \\
\text { integritas data, autentikasi entitas dan autentikasi keaslian data. Kriptografi } \\
\text { sangat dibutuhkan dalam pengamanan data. Salah satu masalah dalam } \\
\text { pengamanan data adalah pencurian data. Pencurian data biasanya dilakukan } \\
\text { untuk melakukan tindakan kejahatan, seperti penyalahgunaan data untuk }\end{array}$ \\
\hline $\begin{array}{l}\text { Keyword: } \\
\text { Kriptografi, Pengamanan Data, } \\
\text { Pesan Teks, Algoritma RSA, } \\
\text { Algoritma DES }\end{array}$ & $\begin{array}{l}\text { kriminalitas. Penulis berkeinginan untuk melakukan pengamanan pesan teks } \\
\text { menggunakan kombinasi algoritma RSA dengan algoritma DES. Jika hanya } \\
\text { menggunakan algoritma RSA, keamanan dari suatu pesan teks masih } \\
\text { terancam. Tingkat keamanan algoritma RSA bergantung pada ukuran kunci } \\
\text { yang dipakai, semakin kecil ukuran kunci maka semakin mudah ditembus } \\
\text { menggunakan metode bruteforce. Pesan teks akan dienkripsi terlebih dahulu } \\
\text { menggunakan algoritma RSA kemudian menggunakan algoritma DES. Dalam } \\
\text { proses dekripsi pesan teks didekripsi menggunakan algoritma DES kemudian } \\
\text { menggunakan algoritma RSA agar mendapatkan plainteks awal. Hasil dari } \\
\text { penelitian ini ditujukan untuk masyarakat, khususnya di bidang keamanan } \\
\text { data. }\end{array}$ \\
\hline
\end{tabular}

Copyright (C) 2021 STMIK Triguna Dharma. All rights reserved.

\author{
Corresponding Author: \\ Nama : Adriansyah Tampubolon \\ Program Studi : Program Studi Teknik Informatika Fakultas Teknik dan Komputer \\ Universitas Harapan Medan \\ Email:
}

\section{PENDAHULUAN}

Dalam perkembangan ilmu pengetahuan dan teknologi saat ini, masalah dalam pengamanan data masih merupakan suatu aspek penting di dalam penyimpanan data, khususnya dokumen yang sangat penting dan sangat sering digunakan dalam kehidupan. Salah satu masalah dalam pengamanan data adalah pencurian data. Pencurian data biasanya dilakukan untuk melakukan tindakan kejahatan, seperti penyalahgunaan data untuk kriminalitas. Dengan adanya kejahatan pencurian data mengakibatkan pengguna merasa tidak aman jika tidak melakukan suatu tindakan dalam mengamankan dokumen yang disimpan. Dalam mengamankan dokumen, dapat dilakukan dengan metode - metode yang ada dalam kriptografi. Kriptografi merupakan ilmu atau seni untuk menjaga atau mengamankan sebuah informasi yang dikirim dari suatu tempat ke tempat lain. Peran kriptografi dalam mengamankan dokumen yaitu menggunakan teknik enkripsi yang menyebabkan dokumen tidak dapat dibaca oleh kriptanalis. Kriptanalis adalah orang yang memecahkan chipertext menjadi plaintext tanpa mengetahui kunci dan algoritma yang digunakan.

Salah satu metode dalam kriptografi adalah algoritma RSA. Algoritma RSA dibuat oleh tiga orang peneliti dari MIT (Massachussets Institute of Technology) pada tahun 1976, yaitu Ron Rivest, Adi Shamir dan Leonard Adleman. Algoritma RSA adalah salah satu teknik kriptografi di mana kunci untuk melakukan enkripsi berbeda dengan kunci untuk melakukan dekripsi. Kunci untuk melakukan enkripsi disebut sebagai kunci publik, sedangkan kunci untuk melakukan dekripsi disebut sebagai kunci private. 
Penulis akan melakukan kombinasi algoritma RSA dengan salah satu algoritma yang cukup kuat dan populer yaitu algoritma DES. Kombinasi dilakukan karena, jika hanya menggunakan algoritma RSA tingkat keamanan dari suatu file masih terancam. Tingkat keamanan algoritma RSA bergantung pada ukuran kunci yang digunakan sebagai sandi. Semakin kecil ukuran kunci, maka semakin mudah ditembus menggunakan metode bruteforce (memeriksa satu per satu kombinasi kunci). Sehingga penulis yakin, jika algoritma RSA dan algoritma DES dikombinasikan akan menghasilkan tingkat keamanan yang bagus, karena rumitnya proses di dalam algoritma DES.

Algoritma DES merupakan algoritma enkripsi yang paling banyak digunakan di dunia yang diadopsi oleh NIST (National Institue of Standards and Technology) sebagai standar pengolah informasi Federal AS. Plaintext dienkrip dalam blok-blok 64 bit menjadi 64 bit data ciphertext menggunakan kunci 56 bit kunci internal (internal key). DES mentransformasikan input 64 bit dalam beberapa tahap enkripsi ke dalam output 64 bit. Dengan demikian, algoritma DES termasuk ke dalam algoritma block cipher. Berdasarkan tahapan dan kunci yang sama, algoritma DES digunakan untuk membalik enkripsi. Kunci internal pada algoritma DES dibangkitkan dari kunci eksternal (external key) 64 bit. Algoritma DES beroperasi pada ukuran blok 64 bit. Algoritma DES mengenkripsikan 64 bit plaintext menjadi 64 bit ciphertext dengan menggunakan 56 bit kunci internal (internal key) atau up-kunci (subkey). Kunci internal dibangkitkan dari kunci eksternal (external key) yang panjangnya 64 bit.

Telah dilakukan sebuah penelitian mengenai implementasi Algoritma Data Encryption Standard pada penyandian record database. Hasil dari penelitian ini membuktikan bahwa penyandian record database berdasarkan algoritma DES mampu mempersulit pihak-pihak lain untuk memahami dan mengerti isi dari record database. [1] (Yanti, N. R et al, 2018)

\section{PERANCANGAN}

Perancangan proses pembangkitan kunci RSA dapat dilihat pada flowchart di bawah ini.

3.

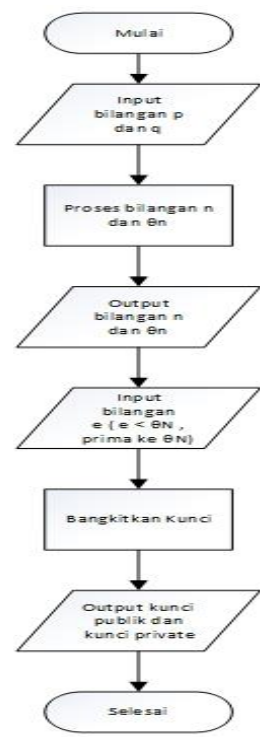

Gambar 1 flowchart kunci RSA

Proses enkripsi dilakukan melalui beberapa tahap, yaitu proses enkripsi menggunakan algoritma RSA kemudian hasil dari proses enkripsi RSA dienkripsi lagi menggunakan algoritma DES. Perancangan proses enkripsi dapat dilihat pada flowchart di bawah ini : 

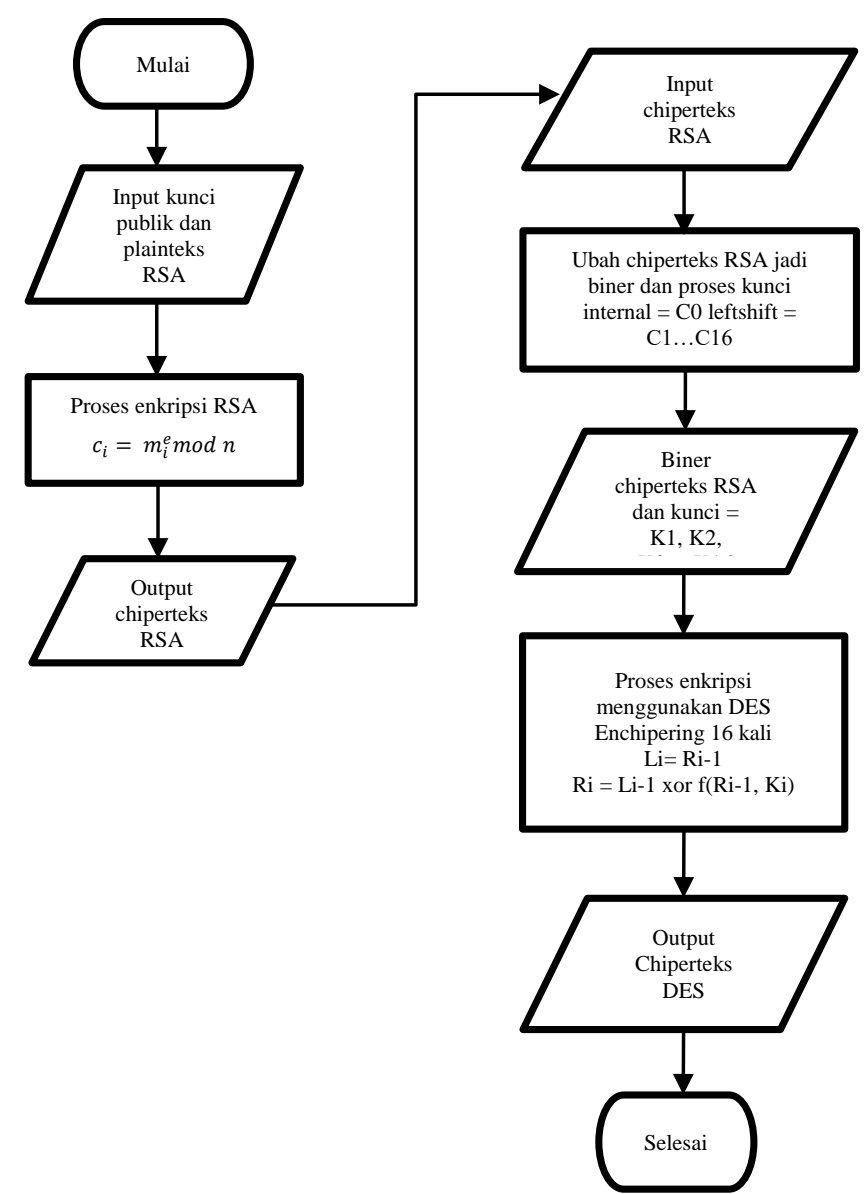

Gambar 2 flowchart proses enkripsi

Proses dekripsi dilakukan melalui beberapa tahap, yaitu proses dekripsi menggunakan algoritma DES kemudian hasil dari proses dekripsi DES didekripsi lagi menggunakan algoritma RSA. Perancangan proses dekripsi dapat dilihat pada flowchart di bawah ini :

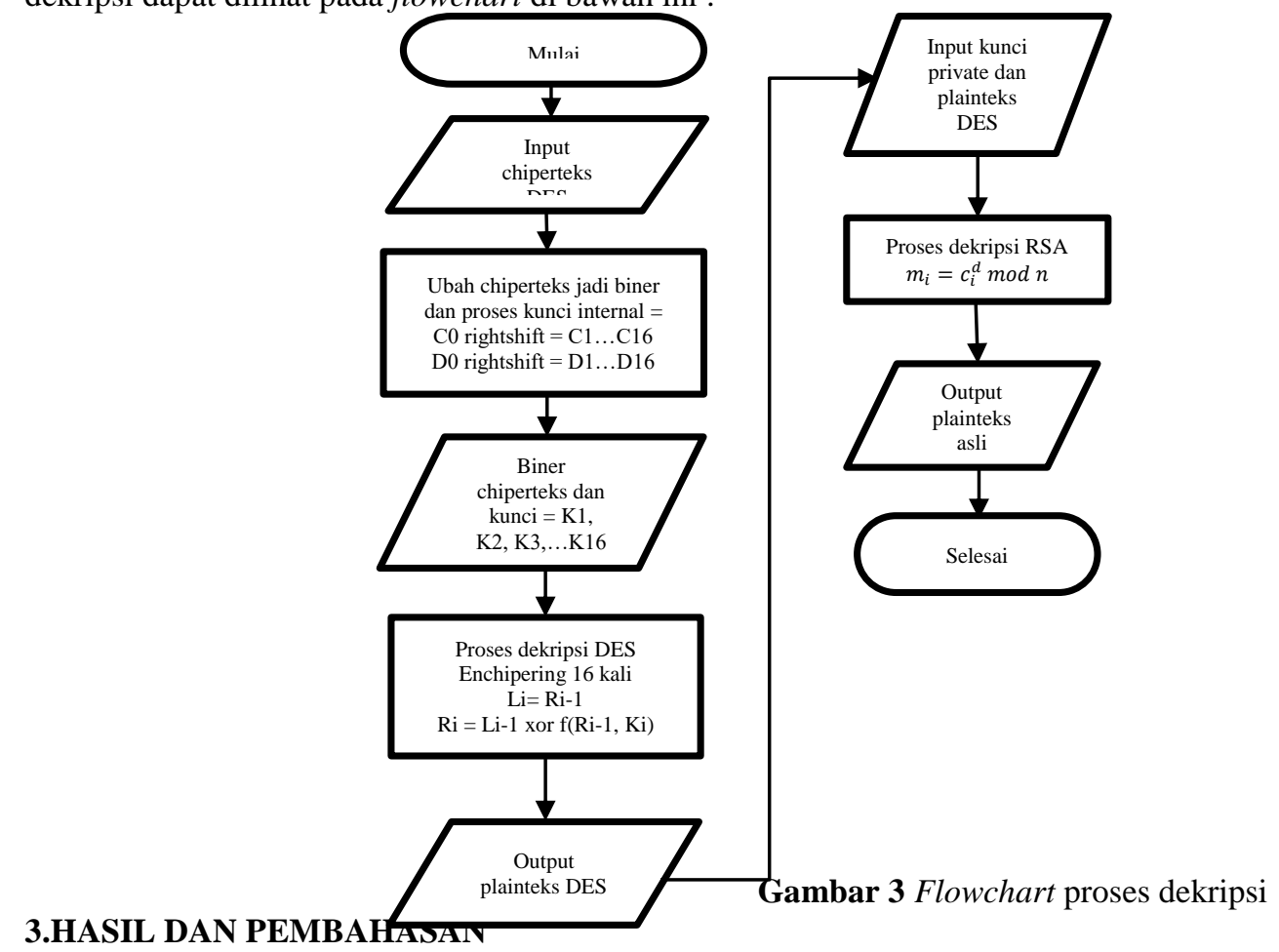


Hasil kombinasi dari algoritma RSA dan algoritma DES dilakukan secara terpisah. Plainteks awal dienkripsi menggunakan algoritma RSA terlebih dahulu. Chiperteks RSA yang berbentuk bilangan desimal dienkripsi lagi menggunakan algoritma DES, sehingga hasil dari enkripsi DES sudah berbentuk simbol - simbol yang tidak dapat dipahami. Pada proses dekripsi juga dilakukan secara terpisah, chiperteks awal didekripsi menggunakan algoritma DES terlebih dahulu, sehingga mendapatkan hasil bilangan desimal. Kemudian chiperteks bentuk desimal didekripsi lagi menggunakan algoritma RSA sehingga mendapatkan plainteks awal.

\subsubsection{Implementasi Form Proses Enkripsi RSA}

Form proses enkripsi RSA akan ditampilkan jika user memilih tab proses enkripsi RSA. Penulis memasukkan kunci publik $=(139,22499)$. Selanjutnya memasukkan plainteks pada kolom yang disediakan. Penulis memasukkan plainteks "Microsoft visual studio 2012 merupakan sebuah perangkat lunak lengkap (suite) yang dapat digunakan untuk melakukan pengembangan aplikasi, baik itu aplikasi bisnis, aplikasi personal, ataupun komponen aplikasinya, dalam bentuk aplikasi console, aplikasi windows, ataupun aplikasi web. Visual studio 2012 mencakup kompiler, sdk, integrated development environment (ide), dan dokumentasi (umumnya berupa msdn library) “.

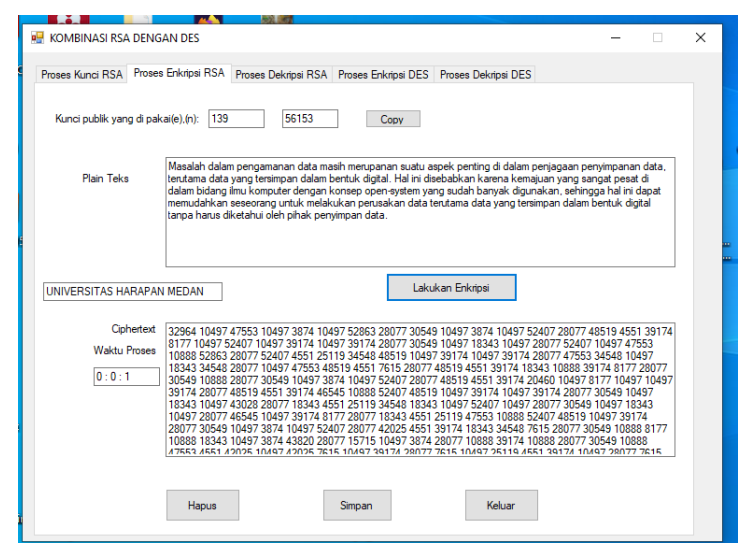

Gambar 3 Implementasi form proses enkripsi RSA

Pada gambar 3 dapat dilihat waktu yang digunakan untuk proses enkripsi RSA adalah 1 detik.

\subsubsection{Impelementasi Form Proses Dekripsi RSA}

Form proses dekripsi RSA akan ditampilkan jika user memilih tab proses dekripsi RSA. Penulis memasukkan kunci private $=(11659,22499)$. Selanjutnya memasukkan chiperteks pada kolom yang disediakan. Penulis memasukkan chiperteks "20722 302457969770174997214174991293912890146791159430247214 1139614212216071467972141289011396693024174991467914170549913788141701467919594 2176897701139672051421278931421217545146797214217681675811396142122092146797205 217689770142121754573367893142121289014679216071139617545142127893146792160721768 175457336789314212720514679155707214113963024128902176813259146799161421217545 7336146796914212720514212128901467969302473361139617545142127893142121754514679 113961754512890113967893146791959421768216071421278931139678931421217545146797205 21768175457336217681959416758142121754573361421217545146791421272052160730247893 1421272143024109821467916758142123024789314679302412890113961467914212720521607 30247893142127214302414679167583024721417545302472141098214679142127205216073024 7893142127214302414679720521768977072141749917545142122160710982146791421212890 142121139672051139617545146797893174991959472051749917545217681754514679142127205 216073024789314212721430241754591614212109821467969142122160714212195941467916758 217681754512890113967893146791421272052160730247893142127214302414679579617499 1754572141749921607217681098214679142127205216073024789314212721430241467911142 3024175456917499111427214109821467914212128901421211396720511396175451467914212 72052160730247893142127214302414679111422176816758890514679380302472141139614212 2160714679721412890113966930241749914679141705499137881417014679195942176817545 5796142127893113967205146797893174991959472053024216072176897701098214679721469 78931098214679302417545128902176873369770142121289021768691467969217681159421768 21607174997205195942176817545128901467921768175451159430249770174991754519594 2176817545128901467915570302469217681325910982146796914212175451467969174997893 113961959421768175451289014212721430241467915570113961959411396195941754591614212 

$142129770916132598905^{\prime}$,

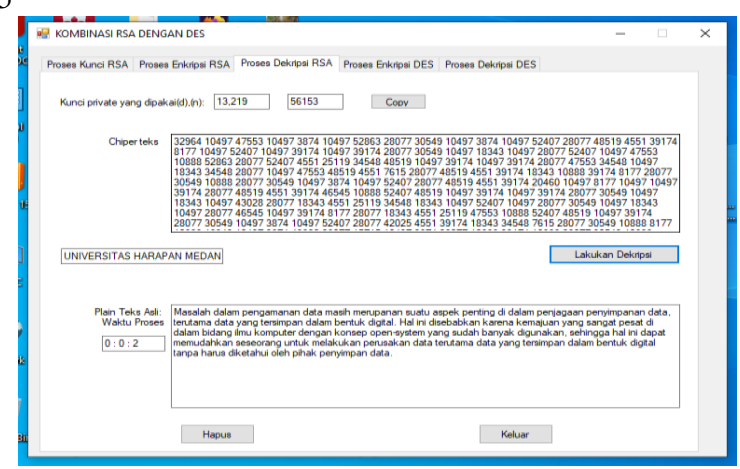

Gambar 4 Implementasi form dekripsi RSA

Pada gambar 3 dapat dilihat waktu yang digunakan untuk proses dekripsi RSA sedikit lebih lama dari proses enkripsi yaitu 2 detik.

\subsubsection{Implementasi Form Proses Enkripsi DES}

Form proses enkripsi DES akan ditampilkan jika user memilih tab proses enkripsi DES. Pada penggunaannya kolom chiperteks RSA akan otomatis terisi pada saat penulis melakukan proses enkripsi RSA sebelumnya.

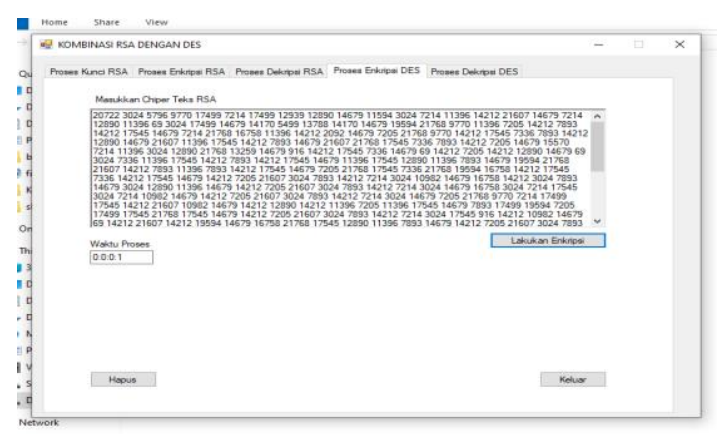

Gambar 5 Implementasi form enkripsi DES

Pada gambar 5 dapat dilihat waktu yang dibutuhkan untuk proses enkripsi DES sama dengan waktu yang dibutuhkan pada proses enkripsi RSA yaitu 1 detik.

\subsubsection{Implementasi Form Proses Dekripsi DES}

Form proses dekripsi DES akan ditampilkan jika user memilih tab proses dekripsi DES. Pada penggunaannya kolom chiperteks hasil enkripsi DES akan otomatis terisi pada saat penulis melakukan proses enkripsi DES sebelumnya.

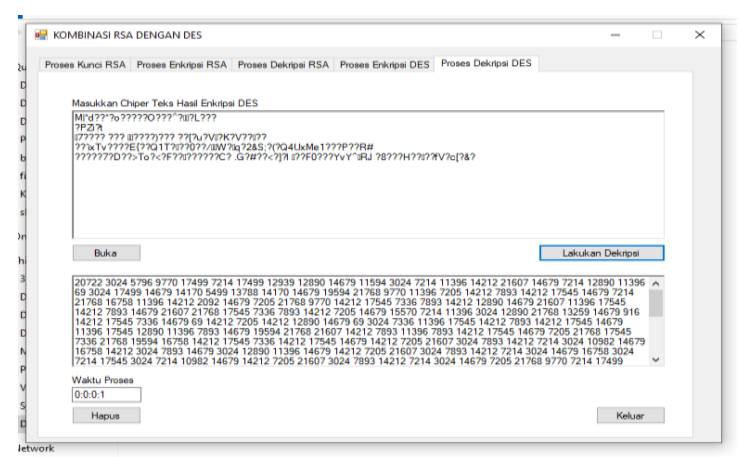

Gambar 6 Implementasi form dekripsi DES 
Pada gambar 6 dapat dilihat waktu yang dibutuhkan untuk proses dekripsi DES sama dengan waktu yang dibutuhkan pada proses enkripsi DES yaitu 1 detik.

\section{PENUTUPAN}

\subsection{Kesimpulan}

Berdasarkan hasil penulisan ini, dapat disimpulkan beberapa hal mengenai implementasi kombinasi Algoritma RSA (Riverst Shamir Adleman) dan Algoritma DES (Data Encryption Standard) pada aplikasi pengaman pesan teks. Kesimpulannya adalah sebagai berikut:

1. Pesan teks diamankan menggunakan kombinasi algoritma RSA dan algoritma DES. Proses pengamanan pada aplikasi ini dilakukan terpisah. Hasil dari enkripsi algoritma RSA dienkripsi lagi menggunakan algoritma DES, begitupula pada proses dekripsinya.

2. Aplikasi yang menerapkan kombinasi algoritma RSA dan algoritma DES ini berjalan dengan baik dan mampu mengenkripsi dan mendekripsi pesan teks sehingga dapat meningkatkan keamaan suatu pesan.

3. Pada aplikasi yang dibangun, satu plainteks dapat menghasilkan bermacam - macam chiperteks menggunakan algoritma RSA dikarenakan proses pembangkitan kunci RSA didasarkan oleh bilangan prima $\mathrm{p}$ dan $\mathrm{q}$ yang diinputkan

4. Hasil dari kombinasi algoritma RSA dan algoritma DES menjadi simbol - simbol yang lebih rumit, sehingga lebih sulit untuk ditembus menggunakan metode bruteforce.

\subsection{Saran}

Berdasarkan hasil penulisan ini, aplikasi dapat dikembangkan lagi agar menjadi lebih baik, sehingga penulis mengajukan beberapa saran. Saran tersebut adalah sebagai berikut:

1. Untuk meningkatkan keamanan algoritma DES, dapat dilakukan penelitian lebih lanjut mengenai pengembangan dari algoritma DES, yaitu algoritma Triple DES.

2. Aplikasi yang dibangun masih memiliki banyak kekurangan, terutama dalam masalah penampungan nilai yang terbatas, diharapkan untuk ke depannya aplikasi dapat dikembangkan agar menjadi lebih baik lagi.

\section{DAFTAR PUSTAKA}

[1] Yanti, N. R., Alimah, A., \& Ritonga, D. A. (2018). Implementasi Algoritma Data Encryption Standard Pada Penyandian Record Database. J-SAKTI (Jurnal Sains Komputer Dan Informatika), 2(1), 23.

[2] Basri. (2016). Kriptografi simetris dan asimetris dalam perspektif keamanan data dan kompleksitas komputasi. Jurnal Ilmiah Ilmu Komputer, 2(2).

[3] Devha, C. (2013). Pengamanan Pesan Rahasia Menggunakan Algoritma Kriptografi Rivest Shank Adleman (RSA). Universitas Pendidikan Indonesia, 39-73.

[4] Donzilio Antonio Meko. (2018). Jurnal Teknologi Terpadu Perbandingan Algoritma DES , AES , IDEA Dan Blowfish dalam Enkripsi dan Dekripsi Data Donzilio Antonio Meko Program Studi Teknik Informatika, STIMIK Kupang Jurnal Teknologi Terpadu. Jurnal Teknologi Terpadu, 4(1), 8-15.

[5] Hasibuan, A. Z., Asih, M. S., \& Harahap, H. (2019). Penerapan QR Code dan Vigenere Cipher Dalam Sistem Pelaporan Juru Parkir Ilegal. Jurnal Sistem Informasi, 5341(April), 53-61.

[6] Kurniawan, R. (2017). Rancang Bangun Aplikasi Pengaman Isi File Dokumen Dengan RSA. Jurnal Ilmu Komputer Dan Informatika, 01(November), 46-52.

[7] Maryanto, B. (2008). Penggunaan Fungsi Hash Satu-Arah untuk Enkripsi Data. Media Informatika, 7(3), $1-10$.

[8] Pahrizal, P., \& Pratama, D. (2016). Implementasi Algoritma Rsa Untuk Pengamanan Data Berbentuk Teks. Pseudocode, 3(1), 44-49.

[9] Primartha, R. (2011). Penerapan Enkripsi Dan Dekripsi File Menggunakan Algoritma Data Encryption Standard (DES). Sriwijaya Journal of Information Systems, 3(2), 371-387. 